1088

\section{MENAGEMENT OF DYSLIPIDEMIJA IN CHILDHOOD OBESITY}

\section{M.J. Nikolovska}

Health Center Skopje, Skopje, FYR Macedonia

Several studies have shown that childhood obesity has been connected to dyslipidemia, which is recognized as a significant risk for atherosclerotic disease. The rationale for management of dyslipidemia in childhood is strong: to limit the development of atherosclerosis, to establish lifelong lifestyle habits, and to prevent the acquisition of additional risk factors. The aim of the study is to present the menagement of dyslipidemia in our pediatric primary health care.

Methods: Our study included 45 children with BMI>95th percentile selected from the local schoolchildren who were following regular continuing health care (aged 8-18 years) and who had no family history of CHD. Children et high risk for obesity-related cardiovascular disease received family-based individualized treatment. After causes of secondary dyslipidemia had been ruled out or treated, dietary therapy was the primary intervention. Ehercises were also included. The diets prescribed were those used in adults, energy intake levels were selected to support growth and development, and to reach or maintain desirable body weight. There was no pediatric patient 10 years of age or older with LDL-cholesterol, wich is the major determinant of atherosclerotic process beginning in childhood that had remained very high despite vigorous lifestyle intervention. Thats why pharmacotherapy was not considered.

Conclusion: In order toreduce the risk of cardiovascular disease it is very important for the practitioner to undertake effective treatment of dyslipidemia in childhood.
1089

\section{BODY COMPOSITION IN LOW BIRTH WEIGHT PRETERM INFANTS DURING THE FIRST TEN DAYS OF LIFE AND AT FULL-TERM CORRECTED AGE}

\author{
E. Olhager ${ }^{1}$, C. Törnqvist ${ }^{2}$
}

${ }^{1}$ Division of Paediatrics, Department of Clinical and Experimental Medicine, Faculty of Health Science, ${ }^{2}$ Pediatrics, Linköping University Hospital, Linköping, Sweden

Background: Low birth weight (LBW) preterm infants are at risk of growth restriction at full-term age and of altered body composition, which can lead to a higher risk of obesity and insulin resistance later in life. The growth restriction at term age can be caused by a lack of growth during the first period of life.

Aim: To study changes in body weight, fat-free mass and fat mass during the first two weeks of life and at full term in healthy LBW infants.

Methods: Using air displacement plethysmography (Pea Pod) in a prospective longitudinal observational study we investigated the fat-free mass and fat mass of 29 LBW preterm infants at 4 days of age and at full-term post conceptional age. 16 infants were investigated four times during the first 10 days.

Results: There was no significant change in birth weight, fat-free mass or fat mass between day 4 and 10 , but there was a $150 \%$ increase in fat mass, $20 \%$ increase in fat free mass and $29 \%$ increase in body weight from day 4 until full-term post conceptionalage.

Conclusion: In LBW preterm infants there is no change in body composition between days 4 and 10. There is a significant distinct catch-up growth in fat mass, compare to fat free mass and body weight between day 4 and full term. 